\title{
Konsep bentuk kujang sebagai salah satu identitas eksistensi budaya Sunda dalam perencanaan taman di Kota Bogor
}

\author{
Daisy Radnawati ${ }^{*}$, Yusi Febriani ${ }^{1}$, Eli Nurhayati ${ }^{1}$ \\ 1. Program Studi Arsitektur Lanskap, Institut Sains dan Teknologi Nasional \\ *E-mail: daisy.arl@istn.ac.id
}

\begin{abstract}
Kujang form concept as an identity of Sundanese culture existence in Bogor urban park planning. City Park is a public space where people gather and do various activities in it. There are several functions of urban parks such as community associations, sports venues, environmental education, health promotion and aesthetic value. Some of the city parks in Bogor are Malabar Park, and Empang Park which is surrounded by residential areas and is mainly used as a sports vessel. Contrary to its function, the activity has not been supported by facilities that can provide user comfort and security. The problems seen in the existing condition of the park in Bogor are generally very bad and unkempt, some of the park has no recreational facilities or other supporting facilities that can be used by the public, has no strong character or identity, and has not connected between parks (connecting park). Researchers collect data through direct observation at the research site. Researchers looked at the entire site including physical aspects (accessibility, entrance, circulation path, road dimension, climatology), biophysical (vegetation and wildlife) aspects, and socio-cultural aspects (park visitor behavior). Observations are used by researchers as additional information in the study. Field survey in this research can be obtained by observation, interview and documentation. The concept of connecting park is applied to provide connectivity between parks that have an identity and can present the elements and appropriate park facilities so as to provide satisfaction, pleasure, comfort, and security to the user. Kujang as traditional weapon of Sundanese applied as the form and design concept of the parks.
\end{abstract}

Keywords: aesthetic value, connecting park, public spaces, Sundanese, thematic parks,

\section{Pendahuluan}

Taman Malabar dan Taman Empang adalah salah satu ruang terbuka yang terletak di Kota Bogor. Diantara taman tersebut belum dikembangkan dengan optimal dan belum memenuhi fungsi sebuah taman kota secara maksimal serta belum memiliki keterhubungan antar taman. Sebagai ruang terbuka yang bersifat aktif, beberapa kondisi taman tersebut sangat buruk dan tidak terawat, bahkan pada Taman Empang belum memiliki perencanaan taman dan belum memiliki fasilitas rekreasi maupun fasilitas penunjang lain yang dapat digunakan oleh umum serta belum memiliki fungsi identitas, estetika dan sosial. Taman tersebut berpotensi dikembangkan menjadi salah satu alternatif taman yang dapat dikunjungi dan menambah wajah baru di Kota Bogor. Dengan menggunakan konsep bentuk yang khas mencirikan Kota Bogor, diharapkan taman tersebut memiliki keterhubungan yang kuat dan dapat didesain sesuai dengan fungsi yang ideal, menghadirkan elemen dan fasilitas taman yang tepat sehingga fungsi tapak optimal dan mampu memberikan kepuasan, kesenangan, kenyamanan, dan keamanan pada pengguna.

Kondisi eksisting taman di lokasi penelitian, selain kondisi taman yang belum tertata, juga belum terlihatnya karakter yang kuat sebagai identitas kota, kurangnya apresiasi masyarakat terhadap keberadaan taman-taman kota (Pusparini et al., 2017). Belum mampunya taman memenuhi kebutuhan warganya dalam melakukan berbagai aktivitas di dalamnya. Fungsi utama beberapa taman belum terlihat jelas dan belum didukung oleh elemen lanskap yang mampu mewadahi kegiatan serta aktivitas penggunanya. Untuk mewujudkan keterhubungan konsep dalam penelitian ini, maka selain perencanaan taman kota, koridor jalanpun perlu di desain agar tercipta kesatuan (unity) dan keterhubungan baik secara tematik maupun keterhubungan aksesibilitas yang dapat memenuhi kebutuhan warganya serta menarik untuk dikunjungi. Kota Bogor yang memiliki Kebun Raya sebagai pusat kota dapat dijadikan sebagai pusat keterhubungan antar 
taman (connecting park) sehingga dapat menjadi dasar dalam perencanaan lanskap koridor jalan dan taman tematik pada masa yang akan datang.

Sebagai salah satu daerah di Tatar Sunda, Kota Bogor selama ini dikenal dengan maskot kujangnya. Hal ini dapat dilihat dari keberadaan Tugu Kujang yang menjadi landmark Kota Bogor selalu dibanggakan oleh masyarakatnya. Namun sangat disesalkan, adabtasi kujang belum banyak terlihat pada lanskap kotanya. Adabtasi kujang juga hanya menggunakan satu jenis kujang padahal kujang sesungguhnya beragam. Ada kujang ciung, kujang jago, kujang kuntul, kujang bangkong, kujang naga, kujang badak, dan kujang pekarangan. Penelitian ini diharapkan dapat menjadi contoh bahwa melalui perencanaan taman dengan konsep bentuk kujang merupakan hal yang sangat memungkinkan. Apabila dapat diwujudkan, maka tamantaman di Kota Bogor dapat menjadi identitas kota ,memberikan nilai estetis dan mampu meningkatkan kualitas ruang terbuka di Kota Bogor.

\section{Metode}

Penelitian ini dilaksanakan di Kota Bogor, Provinsi Jawa Barat. Lokasi yang menjadi objek penelitian dibagi menjadi dua yaitu taman dan koridor. Untuk taman dipilih Taman Malabar dan Taman Empang. Sedangkan untuk koridor yaitu Jalan Raden Saleh Syarif Bustaman, dan Jalan Malabar. Jalan Raden Saleh Syarif Bustaman yang merupakan penghubung ke Taman Empang sedangkan Jalan Raden Syarif Bustaman merupakan penghubung ke Taman Malabar (Gambar 1) Penelitian ini dilaksanakan mulai April hingga Agustus 2016.

Peneliti menggunakan metode pengumpulan data yang terbagi dalam dua tipe yaitu data primer dan data sekunder. Data primer diperoleh dengan cara survei lapang (observasi, wawancara, dan dokumentasi/gambar) ke lokasi atau obyek penelitian. Kegiatan observasi dilaksanakan dengan melakukan identifikasi karakteristik tapak baik secara kuantitatif dengan pengukuran maupun secara kualitatif dengan cara menghubungkan dengan teori, prinsip, dan kaidah suatu produk lanskap. Peneliti mengamati keseluruhan dalam tapak di antaranya adalah aspek fisik (aksesibilitas, entrance, jalur sirkulasi, dimensi jalan), aspek biofisik (vegetasi dan satwa), dan aspek sosial budaya (perilaku pengunjung taman). Kegiatan wawancara dilakukan kepada pengelola dan pengunjung. Data sekunder diperoleh dengan cara studi literatur menelusuri berbagai sumber, ${ }_{2}$ seperti data iklim, regulasi, hasil penelitian, dokumen, dan data dari instansi terkait yang berhubungan dengan penelitian. Data yang telah dikumpulkan dianalisis baik secara deskriptif maupun spasial. Selanjutnya, hasil analisis digunakan dalam penyusunan konsep, siteplan, dan ilustrasi dengan menggunakan perangkat lunak AutoCAD, SketchUP, Lumion, dan Adobe Photoshop. Pendekatan-pendekatan yang digunakan dalam metode ini mengacu pada penelitian sejenis yang pernah dilaporkan oleh Sagala et al. (2017) dan Hasibuan et al. (2016).

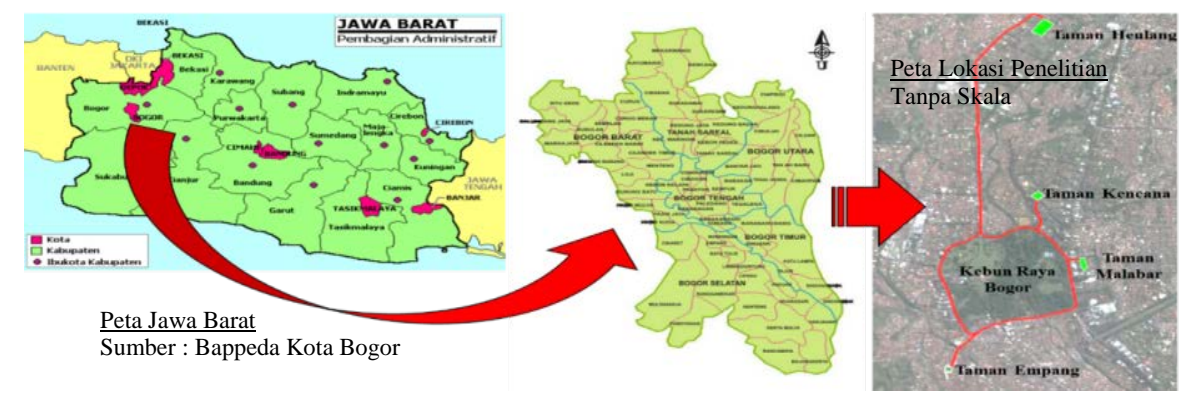

Gambar 1. Lokasi Penelitian

\section{Hasil Dan Pembahasan}

\subsection{Kondisi Umum}

Secara umum Kota Bogor beriklim sejuk, berdasarkan data Badan Pusat Statistik 2014 Kota Bogor memiliki suhu udara rata-rata setiap bulannya mencapai $33,84^{\circ} \mathrm{C}$, kelembaban udara rata-rata setiap bulannya adalah 90,8\%, kecepatan angin rata-rata 1,9 km/jam setiap bulan, curah hujan $390 \mathrm{~mm} / \mathrm{bulan}$, dan hari hujan 13 hari/bulan. Koridor merupakan jalur penghubung antar taman yang terdiri dari koridor utama dan koridor 
penunjang. Koridor utama terdapat pada lingkar Kebun Raya Bogor terdiri dari Jalan Otto Iskandardinata, Jalan Ir. H. Juanda, Jalan Jalak Harupat dan Jalan Pajajaran. Koridor penunjang adalah penghubung dari koridor utama menuju taman yang terdiri dari Jalan Raden Saleh Syarif Bustaman yang merupakan penghubung ke Taman Empang, dan Jalan Malabar merupakan penghubung ke Taman Malabar.

\subsubsection{Taman Malabar}

Taman Malabar terletak di Jalan Malabar, Kelurahan Babakan, Kecamatan Bogor Tengah, Kota Bogor, Jawa Barat. taman tersebut memiliki luasan sekitar $\pm 4.624 \mathrm{~m}^{2}$. Berdasarkan pengamatan kondisi hardscape di Taman Malabar sangat buruk atau rusak dan tidak terawat diantaranya adalah bangku taman, tempat sampah, lampu taman dan lain sebagainya. Keberadaan taman yang kurang terawat ini lah pengunjung enggan untuk datang, sehingga taman kurang diminati pengunjung. Perilaku pengunjung di Taman Malabar berdasarkan pengamatan sering dikunjungi oleh anak-anak, remaja dan dewasa, namun pada saat Aktivitas sosial yang dilakukan di weekday didominasi oleh remaja. Aktivitas pada saat weekday pada taman ini adalah duduk-duduk dan berkumpul. Sedangkan aktivitas pada saat weekend adalah jogging, bermain sepak bola, olah raga pull up, duduk-duduk, dan berkumpu (Gambar 2).

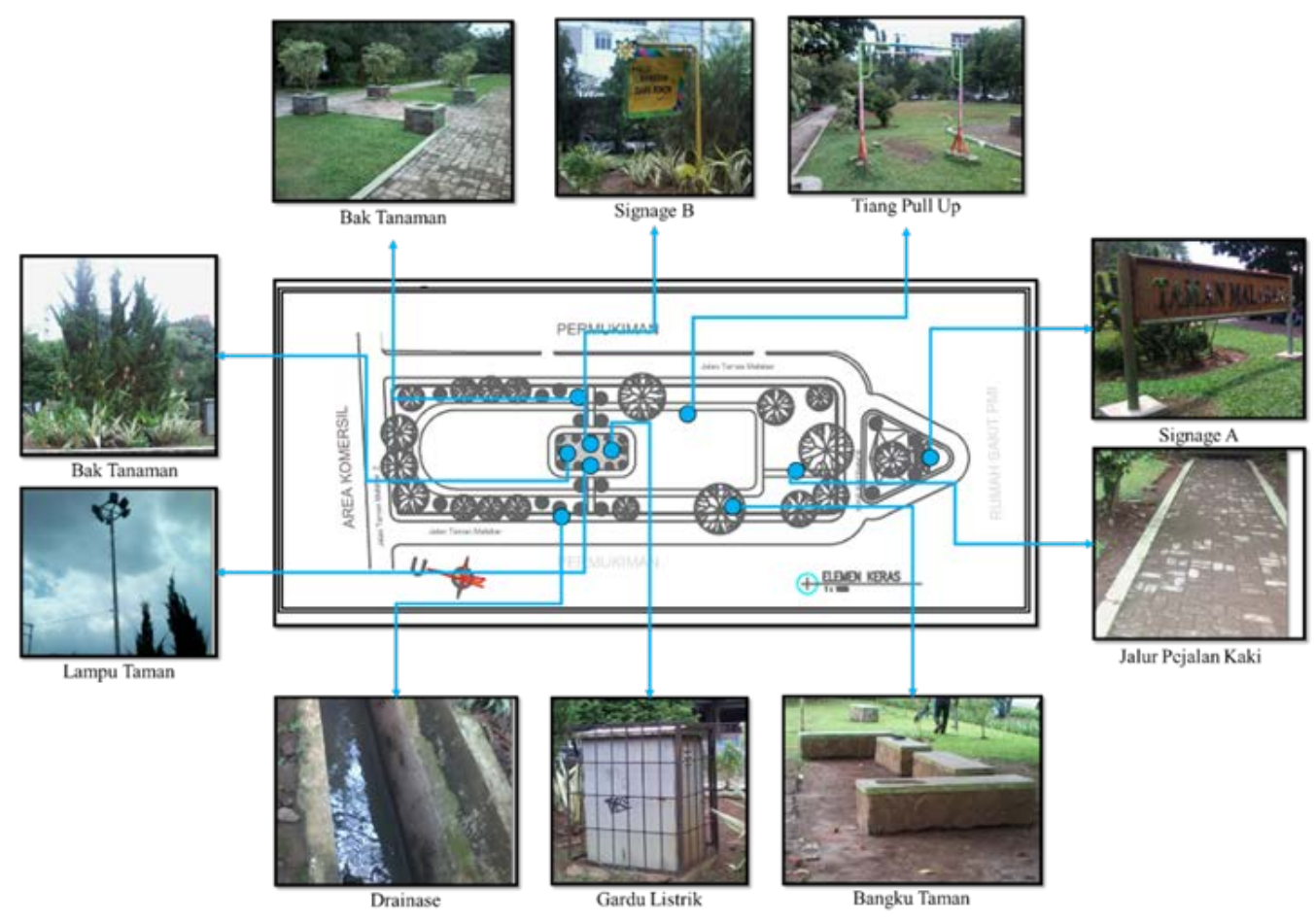

Gambar 2. Kondisi Eksisting Taman Malabar

Taman Malabar memiliki tiga pintu masuk. Pintu masuk pertama berada di sebelah selatan tepatnya di samping Rumah Sakit PMI Bogor. Sedangkan pintu masuk kedua dan ketiga berada di sebelah barat dan timur yang berhadapan dengan permukiman warga sekitar. Taman ini memiliki sirkulasi hanya untuk pejalan kaki dengan lebar $\pm 1,2$ meter. Taman Malabar memiliki pola sirkulasi spiral, karena berasal dari satu titik yang mengelilingi pusatnya dengan jarak yang berubah, bergerak melingkar atau berputar mengelilingi titik pusat tersebut, dan semakin jauh dari titik pusat (Gambar 3). 


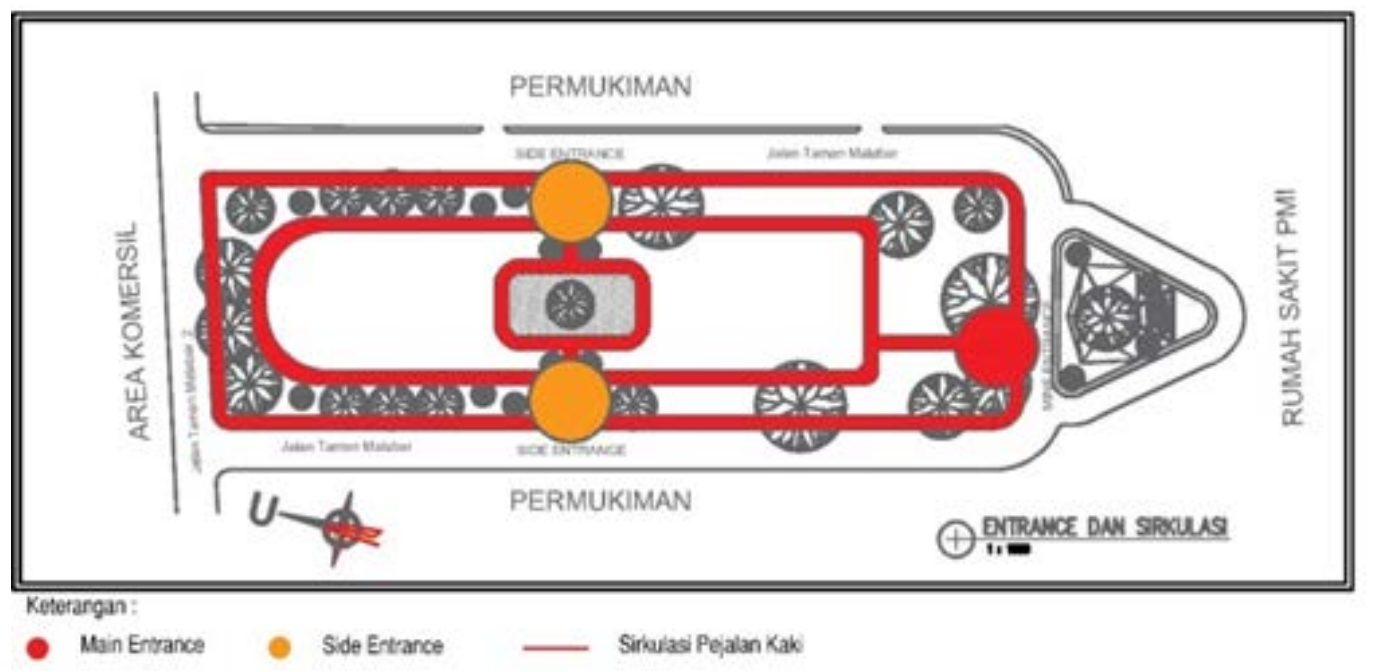

Gambar 3. Entrance dan Sirkulasi Taman Malabar

\subsubsection{Taman Empang}

Taman Empang berada di Jalan Empang, Kelurahan Empang, Kecamatan Bogor Selatan. Taman tersebut memiliki luasan sekitar $\pm 3800 \mathrm{~m}^{2}$. Kondisi Taman Empang saat ini adalah lahan kosong yang dibiarkan begitu saja tanpa adanya pemanfaatan lahan, karena belum adanya perencanaan taman pada tapak. Sehingga pada tapak belum adanya fasilitas hardscape yang menunjang, hanya terdapat lampu taman dan sirkulasi pejalan kaki yang berada di sekeliling tapak dengan lebar 1,2 $\mathrm{m}$. Jalur pedestrian yang ada saat ini dimanfaatkan oleh pedagang kaki lima untuk berjualan di sekeliling tapak. Banyaknya pedagang kaki lima yang berjualan di sekeliling tapak, sehingga keberadaan tapak tidak dapat terlihat. Aktifitas sosial yang dilakukan di Taman Empang sangat sedikit dikarenakan belum ada perencanaan di taman ini. Aktifitas yang ada baik weekday maupun weekend adalah bermain bola, dan bermain layangan (Gambar 4).

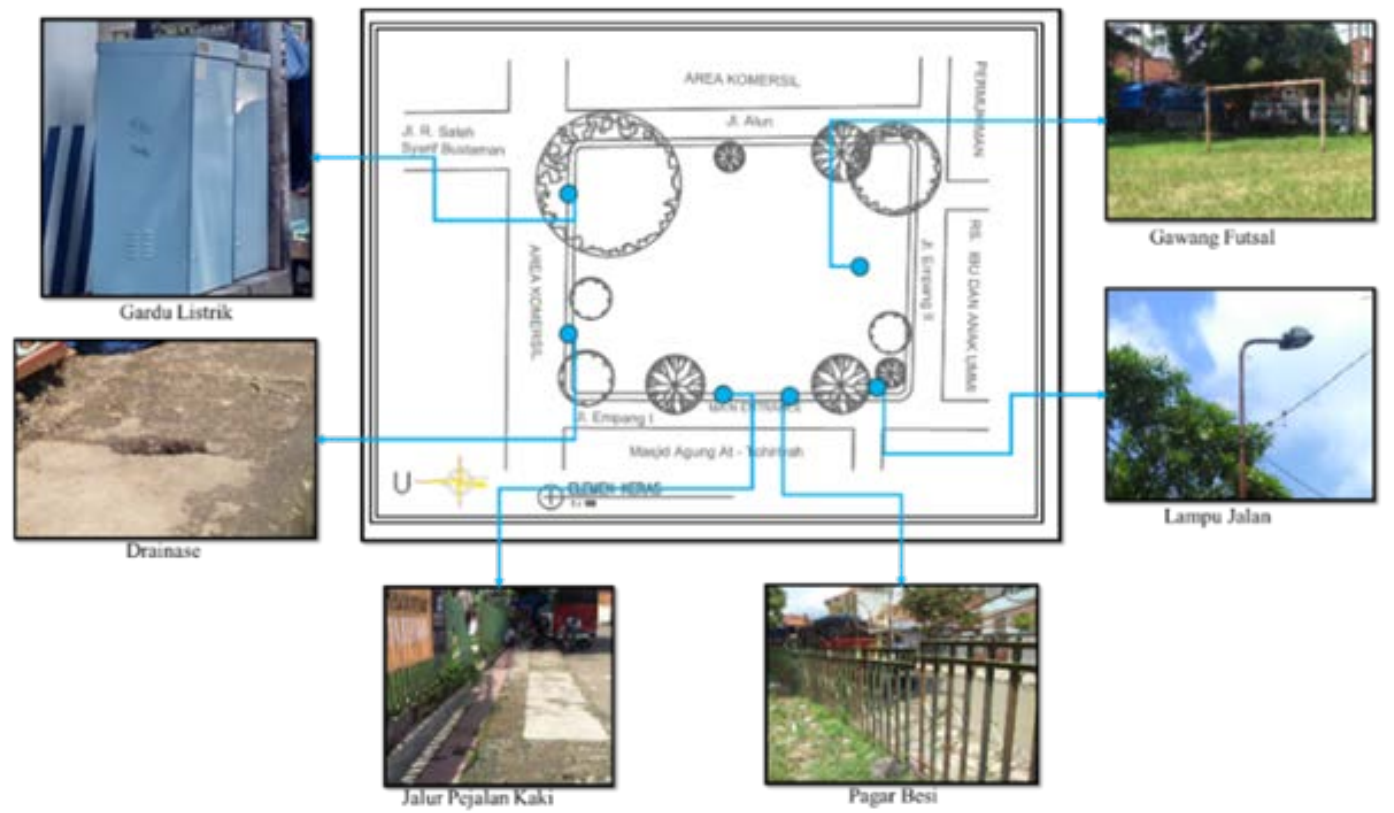

Gambar 4. Kondisi Eksisting Taman Empang

Taman Empang hanya memiliki satu pintu masuk yakni berada di sebelah barat tepatnya berada didepan Masjid Agung At-Tohiriyah. Sirkulasi yang terdapat pada tapak ini hanya sirkulasi untuk pejalan kaki. 
Sirkulasi ini berada di batas luar yang mengelilingi tapak. Taman Empang tersebut memiliki pola sirkulasi linear, karena pola sirkulasi berupa satu atau dua arah, polanya sederhana, pencapaian mudah terhadap tapak (Gambar 5).

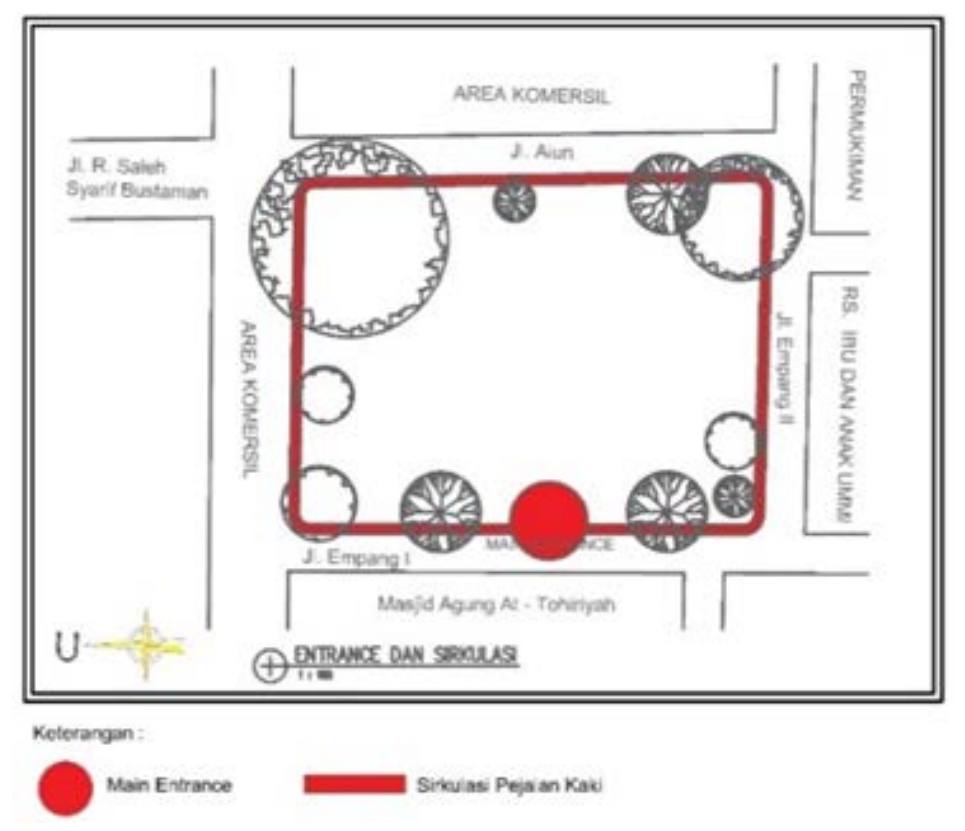

Gambar 5. Entrance dan Sirkulasi Taman Empang

\subsection{Analisis}

\subsubsection{Analisis Fungsi}

Analisis fungsi dideskripsikan dari aktifitas, pengguna, fasilitas, fungsi pengguna, yang menghasilkan kebutuhan ruang dan hubungan antar ruang. Pada Taman Malabar dan Empang hampir seluruh pengguna dari tiga kategori usia (anak-anak, remaja, dan dewasa) memiliki ruang untuk memanfaatkan taman. Fungsi yang menonjol pada taman yaitu fungsi sosial dan budaya. Meskipun demikian, pada Taman Empang kegiatan di taman tidak begitu variatif dibandingkan Taman Malabar (Tabel 1 dan 2).

Tabel 1. Analisis Fungsi Taman Malabar

\begin{tabular}{clllc}
\hline Fungsi & \multicolumn{1}{c}{ Kegiatan } & Pengguna & Fasilitas Utama & Ruang \\
\hline ES, SB & Akses keluar masuk tapak & A, R, D & Pintu masuk, sculpture & $\mathrm{P}$ \\
SB & Berjalan kaki & A, R, D & Jalan setapak & $\mathrm{I}$ \\
ES, SB & Duduk-duduk & A, R, D & Bangku, tempat sampah & $\mathrm{I}$ \\
ES & Menikmati pemandangan & A, R, D & Lawn & $\mathrm{I}$ \\
ES, SB & Berkumpul & A, R, D & Gazebo, plaza & $\mathrm{I}$ \\
SB & Berlari & A, R, D & Lawn & $\mathrm{I}$ \\
SB & Bermain anak & A & Area bermain & I \\
EK & Konservasi tanah & - & Tanaman berstata & H \\
SB & Relaksasi & A, R, D & Jalur refleksi & I \\
\hline
\end{tabular}

Keterangan: $(\mathrm{ES})$ = estetika; $(\mathrm{SB})$ = sosial budaya; $(\mathrm{EK})$ = ekologi; $(\mathrm{A})$ = anak-anak; $(\mathrm{R})$ = remaja; $(\mathrm{D})$ = dewasa; $(P)=$ Penerima; $(I)$ = interaksi; $(H)=$ hijau; $(-)=$ tidak ada. 
Tabel 2. Analisis Fungsi Taman Empang

\begin{tabular}{clclc}
\hline Fungsi & \multicolumn{1}{c}{ Kegiatan } & Pengguna & Fasilitas Utama & Ruang \\
\hline ES, SB & Akses keluar masuk tapak & A, R, D & Pintu masuk & $\mathrm{P}$ \\
SB & Berjalan kaki & A, R, D & Jalur pedestrian & I \\
ES, SB & Duduk-duduk & A, R, D & Bangku taman & I \\
SB & Bermain anak & A & Area bermain anak & I \\
ES & Menikmati pemandangan & A, R, D & Lawn & I \\
ES, SB & Berkumpul & A, R, D & Gazebo, plaza & I \\
EK & Konservasi tanah & - & Tanaman Berstrata & H \\
\hline
\end{tabular}
Keterangan: $(\mathrm{ES})$ = estetika; $(\mathrm{SB})$ = sosial budaya; $(\mathrm{EK})$ = ekologi; $(\mathrm{A})$ = anak-anak; $(\mathrm{R})$ = remaja; $(\mathrm{D})$ = dewasa;

$(P)=$ Penerima; $(I)$ = interaksi; $(H)=$ hijau; $(-)=$ tidak ada.

Fungsi Estetik pada tapak akan diterapkan pada elemen lanskap baik hard maupun soft, fungsi ini diharapkan dapat memberikan ciri khusus dari tapak juga dapat memberikan kesan visual yang menarik bagi pengunjung. Dari fungsi ekologis akan diaplikasikan dengan penataan pohon berstrata agar dapat melindungi tanah dari kerusakan dan menjadi penyedia oksigen bagi lingkungan sekitarnya. Penataan fasilitas penunjang seperti lampu taman, tempat sampah, bangku taman yang menarik serta pola paving yang tidak terkesan monoton diharapkan dapat memberikan identitas pada tapak sehingga terciptanya elemen lanskap yang harmonis serta memberikan karakter pada taman tersebut.

\subsubsection{Analisis Zonasi}

Analisis Zonasi dilakukan menggunakan pendekatan bentuk tapak dan lingkungan sekitar, topografi, dan aktifitas sesuai dengan tabel analisis fungsi sehingga dihasilkan tiga zonasi yaitu zona penerima (welcome area), zona Interaks,i dan zona Hijau (Gambar 6).
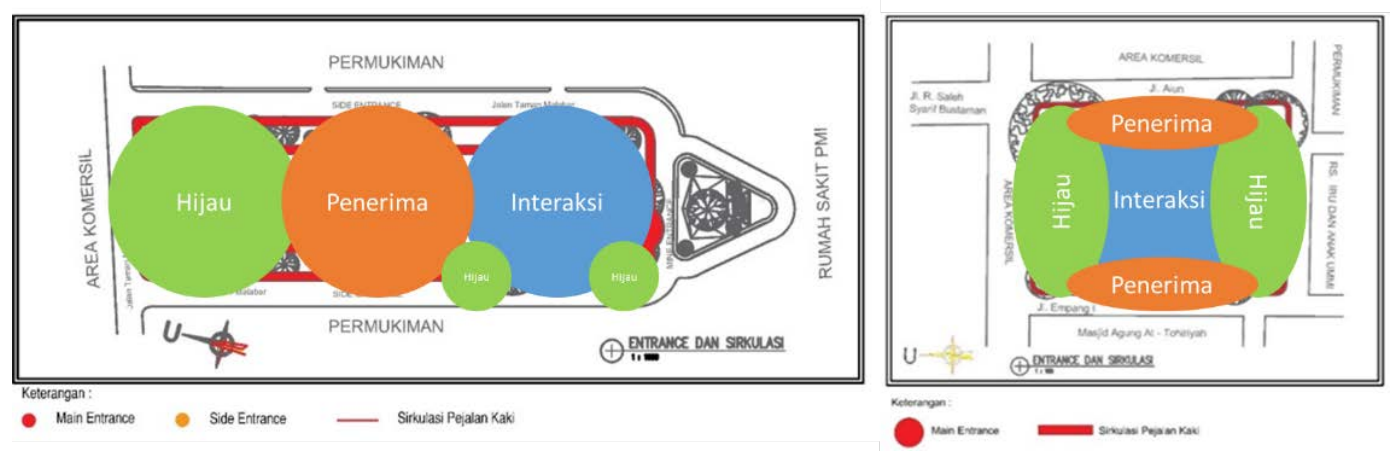

Gambar 6. Zonasi Ruang Taman Malabar (kiri) dan Taman Empang (kanan)

\subsubsection{Analisis Sirkulasi}

Sirkulasi di dalam Taman Malabar dan taman Empang hanya berpola linear dimana pengunjung datang, parkir, berjalan-jalan, duduk, bermain, kemudian pulang, untuk itu akan dibuat pola sirkulasi sesuai dengan pola ruang dan aktivitas yang ada di dalam tapak. Pola-pola sirkulasi yang dapat digunakan antara lain pola linear, pola radial, pola spiral, pola network dan pola campuran.

\subsubsection{Analisis Bangunan Lanskap}

Kondisi jalur pedestrian yang tidak terlalu baik sehingga dapat membahayakan pengguna/pengunjung, serta fasilitas lain bangku taman, tempat duduk, lampu dan tempat sampah yang kurang menarik maka akan membuat perencanaan fasilitas dengan material yang sesuai dengan konsidi tapak (Gambar 7). 

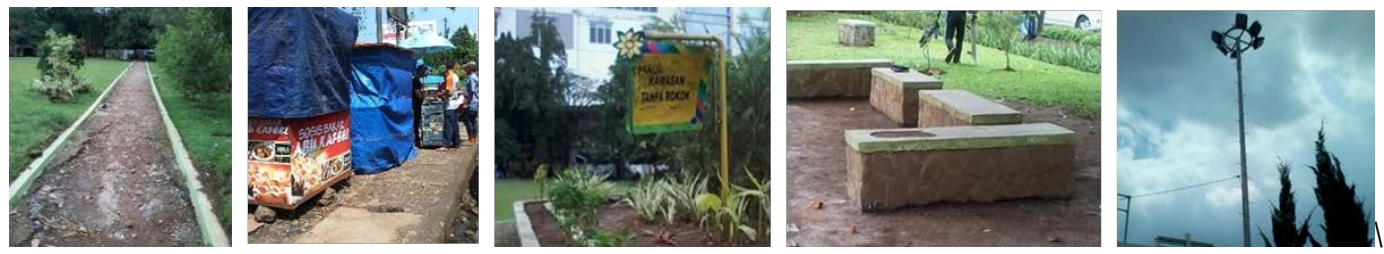

Gambar 7. Elemen lanskap

\subsubsection{Analisis Vegetasi}

Vegetasi pada tapak didominasi tanaman dengan fungsi peneduh dengan penanaman yang menyebar dan tidak teratur. Selain itu belum ada vegetasi yang berfungsi sebagai estetis sehingga terlihat monoton. Untuk itu akan dilakukan seleksi vegetasi menyesuaikan dengan data klimatologi dan disusun berdasarkan kondisi naungan dalam memilih vegetasi yang akan digunakan pada tapak.

\subsection{Konsep}

\subsubsection{Konsep Bentuk}

Pada zaman Kerajaan Pajajaran, Kujang memiliki beberapa bentuk diantaranya adalah kujang bangkong, kujang ciung, kujang naga, dan kujang jago. Dalam penelitian ini Berdasarkan potensi dan permasalahan yang ada pada tapak maka konsep bentuk yang akan diaplikasikan kedalam tapak pada Taman Malabar adalah bentuk kujang jago, dan Taman Empang menggunakan konsep bentuk kujang bangkong (Gambar 8).
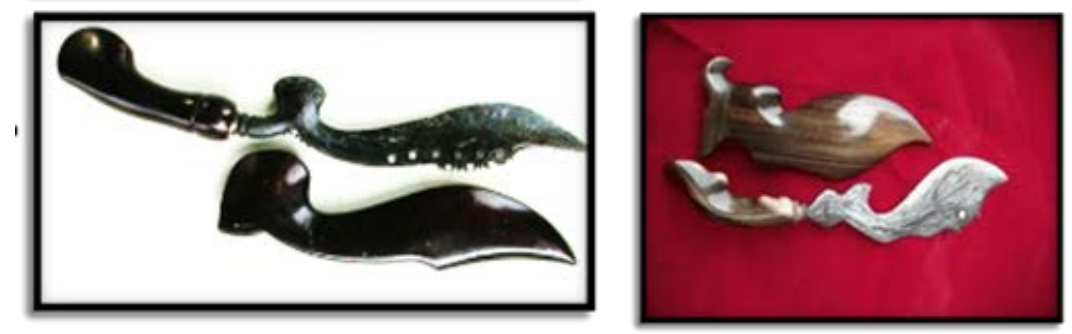

Gambar 8. Bentuk Kujang Jago (kiri) dan Kujang Bangkong (kanan)

\subsubsection{Konsep Sirkulasi}

Konsep sirkulasi yang akan digunakan merupakan penggabungan antara pola linear, pola radial dan campuran sehingga pengguna atau pengunjung dapat mengelilingi tapak serta ruang-ruang yang ada di tapak.

\subsubsection{Konsep Warna}

Aplikasi dari konsep warna pada penelitian ini dituangkan dalam pemilihan jenis vegetasi yang memiliki warna bunga atau daun yang sesuai dengan warna dasar dari bentuk kujang yang dipilih, juga pada pemilihan material fasilitas atau bangunan lanskap yang ada. Konsep warna yang digunakan pada Taman Kujang Jago (Taman Malabar) adalah warna hitam, merah dan jingga (Gambar 9). Karena warna tersebut identik dengan ayam jago atau ayam jantan. Warna yang akan digunakan pada Taman Kujang Bangkong (Taman Empang) adalah hijau, biru dan coklat. Warna hijau diambil dari kodok yang identik dengan warna hijau. Warna biru dan coklat berasal dari air dan tanah sebagai habitat kodok (Gambar 10).

\subsubsection{Konsep Bentuk pada Elemen Hardscape}

Beberapa elemen hardscape yang direncanakan pada koridor jalan sebagai penghubung antar taman menggunakan bentuk dasar kujang yang diimplementasikan pada bentuk signage, sehingga diharapkan dapat memperkuat identitas pada masing-masing koridor taman serta dapat dirasakan sebagai satu kesatuan dengan lingkungan sekitarnya. Koridor jalan Raden Saleh Syarif Bustaman yang merupakan penghubung ke Taman Empang dan Jalan Malabar merupakan penghubung ke Taman Malabar. Signage dengan ketinggian 1,75-2,65 meter (Keputusan Menteri Perhubungan Nomor 61 Tahun 1993) dengan jarak penempatan signage pada koridor jalan per $100 \mathrm{~m}$, menggunakan material besi dengan warna cat yang disesuaikan dengan konsep warna pada masing-masing taman. Sclupture pada tiap taman juga dengan konsep bentuk kujang. Ketinggian 
yang digunakan 1,5-2 meter dan bermaterial besi. Sculpure ditempatkan di zona penerima dengan permainan lampu dan unsur air sehingga dapat memberi suasana berbeda di malam hari (Gambar 11).

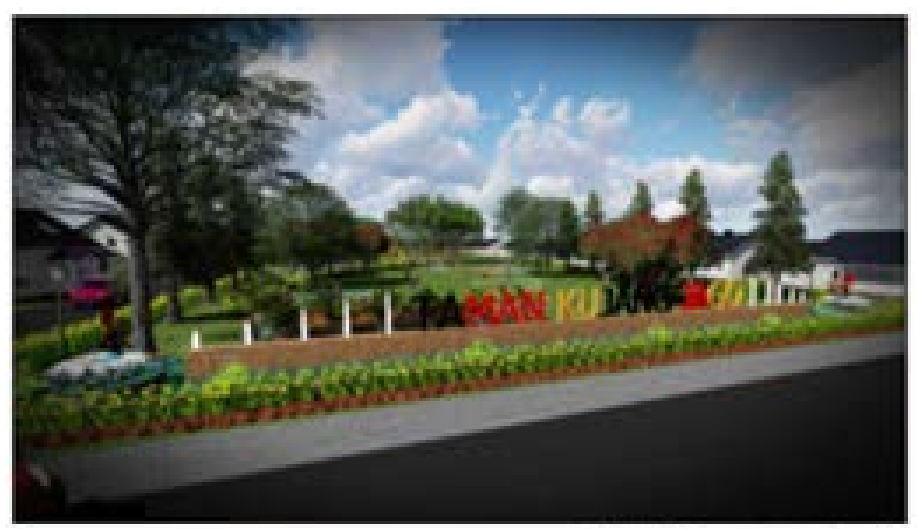

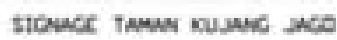

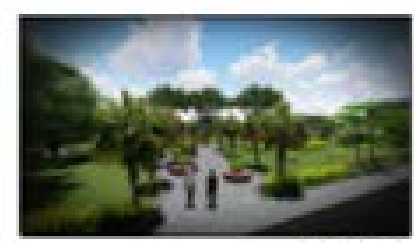

ortewer

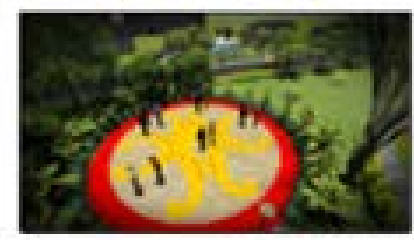

Raza potcencs:

Gambar 9. Aplikasi konsep warna Taman Kujang Jago
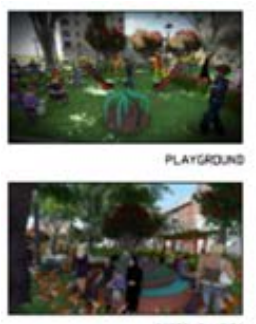

IIIING Mech

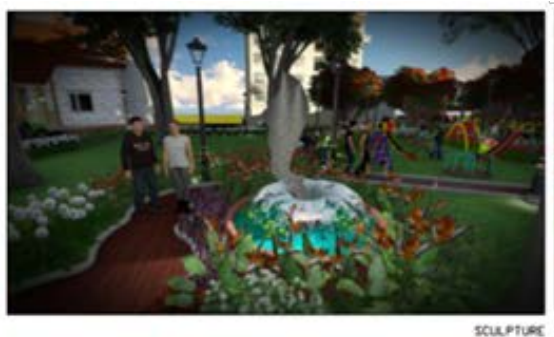

Gambar 10. Konsep Warna Taman Kujang Bangkong

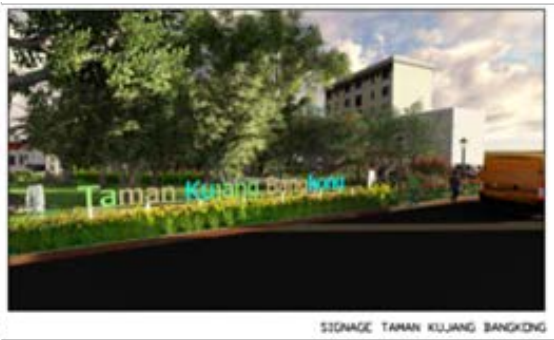

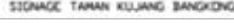

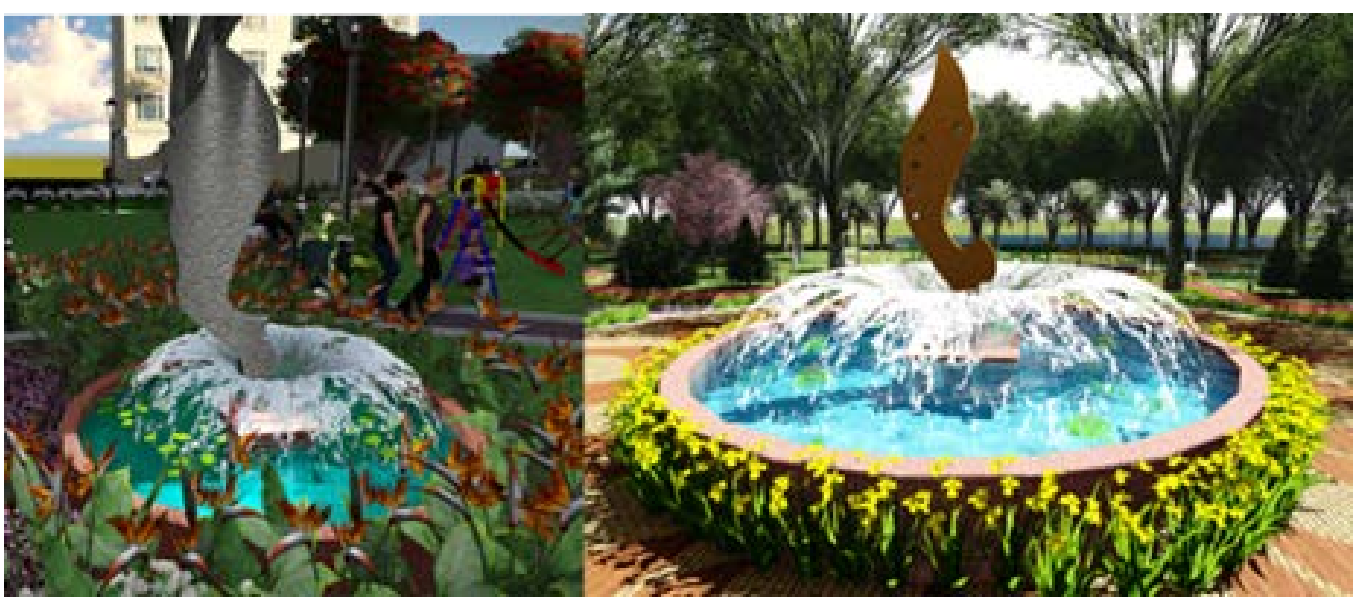

Gambar 11. Konsep Bentuk Sclupture

Perencanaan pola jalur pedestrian pada koridor jalan dan pada area disekeliling taman akan disesuaikan dengan bentuk kujang pada setiap taman tersebut. Jalur pejalan kaki ini memiliki lebar 1,5 - 3 meter dengan menggunakan material paving block berwarna. Untuk lebih mewujudkan harmonisasi bentuk, pola dan warna pada masing-masing koridor jalan dan taman tersebut, maka pola lantai pada Plaza atau area penerima yang berbentuk lingkaran dengan diameter 10-20 meter tersebut juga menggunakan bentuk kujang sesuai tema dari masing-masing taman (Gambar 12). 


\subsubsection{Konsep Vegetasi}

Vegetasi yang digunakan pada tapak merupakan vegetasi pilihan yang dapat tumbuh di dataran tinggi dan berfungsi sebagai pengarah, peneduh dan estetika dengan pola penanaman seperti pola distribusi sebagai pengarah, pola hierarki untuk memberikan kesan alami, pola linear, dan pola penanaman konsentris, serta berfungsi sebagai focal point yang dapat dilihat pada siteplan (Gambar 13).

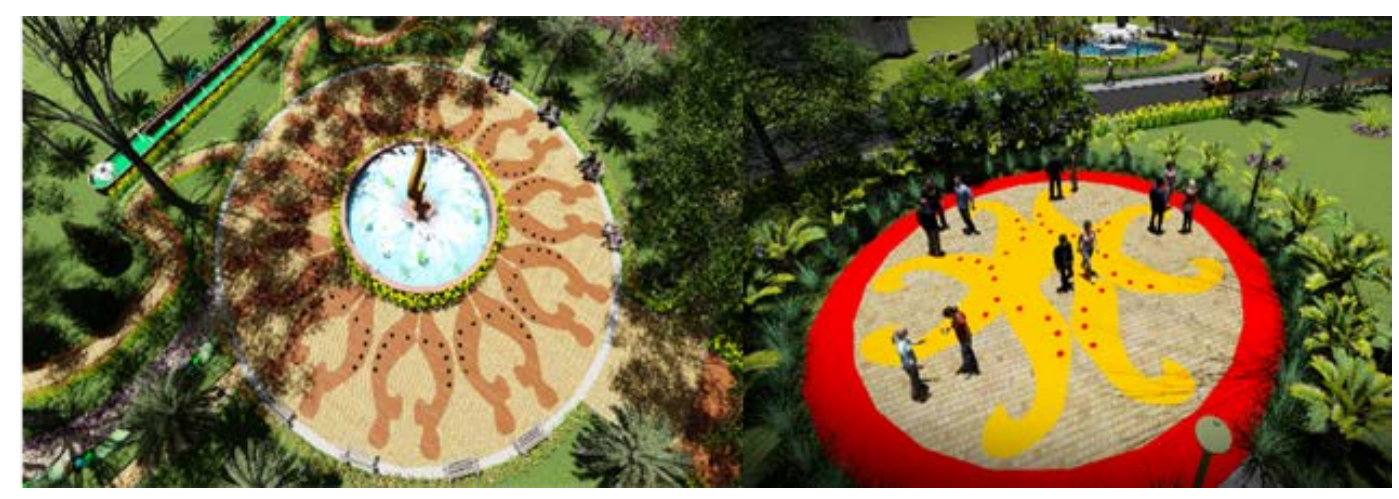

Gambar 12. Pengaplikasian Konsep Kujang pada Pola Lantai
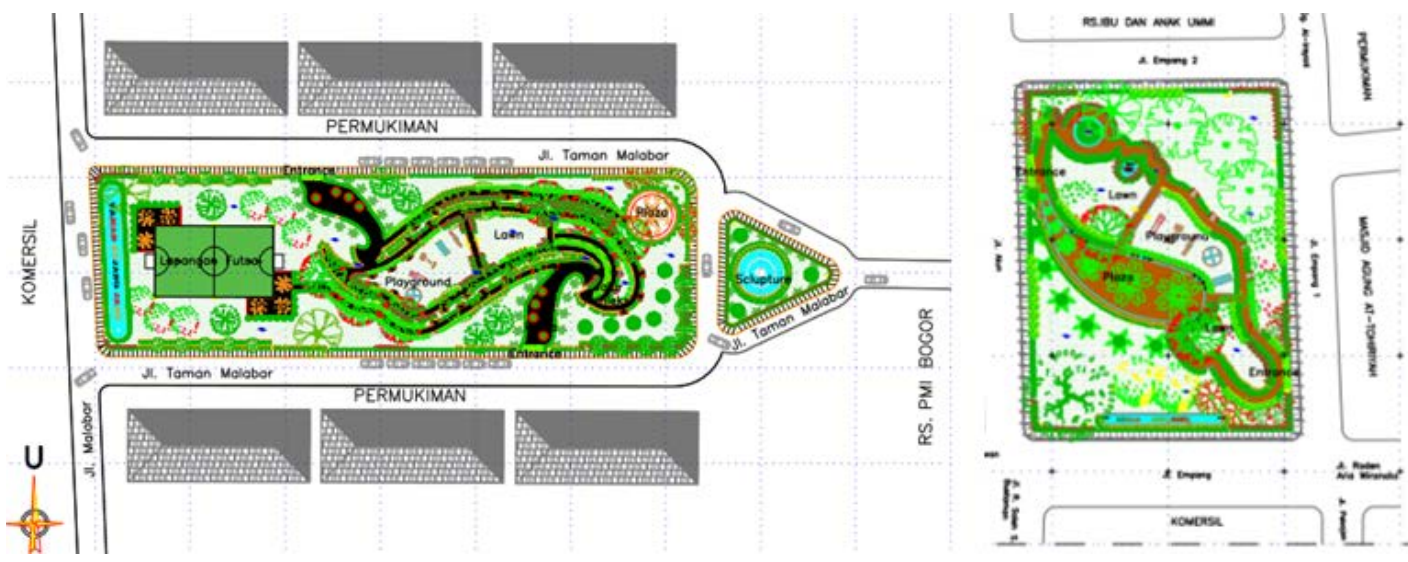

Gambar 13. Siteplan Taman Malabar (kiri) dan Taman Empang (kanan)

\section{Simpulan dan Saran}

Sebagai tempat untuk berinteraksi khususnya masyarakat lokal, taman wajib dikembangkan untuk menambah fungsi ruang hijau dengan sentuhan budaya lokal. Perencanaan taman dengan konsep bentuk kujang adalah salah satu pendekatan dalam merancang taman kota yang mengedepankan fungsi taman sebagai RTH dan ruang interaksi dengan mengangkat bentuk budaya Jawa Barat. Apabila diwujudkan, perencanaan taman di Kota Bogor dengan konsep bentuk kujang ini akan menjadi identitas, memberikan nilai estetis, serta mampu meningkatkan kualitas ruang terbuka di Kota Bogor.

\section{Daftar Pustaka}

Hasibuan, M.S.R., Syahadat, R.M., Nuraini, Arifin, N.H.S. 2016. Perencanaan Jalan Suryakencana - Siliwangi sebagai Ruang Intepretasi Budaya di Kawasan Pecinan Kota Bogor. Buana Sains, 16(1):71-82.

Sagala, A.R., Prasetyo, A., Syakur, D.A., Amania, N.R., Radnawati, D., Syahadat, R.M., Putra, P.T. 2017. Perencanaan Taman Kota sebagai Salah Satu Atribut Kota Hijau di Kecamatan Gedebage, Bandung. Vitruvian Jurnal Arsitektur, Bangunan, \& Lingkungan, 6(3):85-90.

Pusparini F.D., Nurhayati, Arifin, H.S. 2018. Landscape Management of Public Open Space in Bogor Heritage City. IOP Conf. Ser.: Earth Environ. Sci, 91(2017):1-7. 